\title{
Knowledge of the Negative Effects of Cigarette Smoking on Health and Well-Being among Southern Nigerian Youth
}

\author{
Catherine O. Egbe, Inge Petersen, and Anna Meyer-Weitz
}

\begin{abstract}
This mixed methods study investigates the knowledge of youth aged 18 to 24 years about the negative health effects of cigarette smoking. Qualitative interviews were conducted with 18 young smokers. Survey participants comprised 550 youth (irrespective of smoking status). Data was analyzed using the software Nvivo 9 and the Statistical Package for the Social Sciences (SPSS) version 19. Most young smokers recounted some health hazards associated with smoking but expressed a sense of invincibility to the hazards of smoking. Some resorted to reducing their daily consumption of cigarettes or taking cancer protective foods to avoid the health consequences of their smoking habit. Just over half of survey participants $(56.1 \%, n=305)$ had a high knowledge level of the negative health effects of cigarette smoking. This was significantly higher among; non-smokers, females, students, respondents who had never smoked. There is need to raise more awareness in the population on the dangers of smoking.
\end{abstract}

Index Terms-Cigarette, health and well-being, knowledge, Nigeria, youth.

\section{INTRODUCTION}

Cigarette smoking is said to be responsible for over 25 diseases in humans some of which include chronic bronchitis, ischaemic heart disease and cancers of the lung, oral cavity, urinary bladder, pancreas, and larynx [1], [2]. Cigarette smoking has also been implicated either as a contributory factor or causal agent in the following health conditions: osteoporosis, blindness, impotence, loss of teeth, diabetes, reduced fertility, cataracts, asthma, reduced sperm count, fungal eye infection, early menopause, stomach ulcers, cardiovascular heart diseases, reduced lung function, reduced lung growth, and atherosclerosis [3], [4]. Smokers also face a much greater risk of premature death than non-smokers [4] [5]. Unfortunately, these health implications are not the exclusive preserve of active smokers but are also shared by passive or second-hand smokers [4], [6], [7]. There are suggestions based on research that smoking tends to cause cognitive decline and results in the loss of grey matter tissue in the brain with time [8]. At the end of the twentieth century, deaths from smoking related illnesses had risen to 4 million a year worldwide and projections indicate that this could rise to 10 million a year by 2030 [4].

In a nutshell, smoking harms the lungs, heart, arteries, brain, kidneys, bladder, skin and eyes; even unborn children

Manuscript received August 13, 2014; revised November 2, 2014. This work was supported in part by the University of KwaZulu-Natal (UKZN) Doctoral Research Grant received by the first author in 2012.

The authors are with UKZN, Durban 4041, South Africa (e-mail egbe@ukzn.ac.za, meyerweitza@ukzn.ac.za). whose mothers are either active or passive smokers. Smoking speeds up the aging process and raises blood pressure, harming the unborn baby directly by lowering birth weight and increasing the unborn child's susceptibility to disease [6].

The major components of cigarette that constitute the greatest health hazard are nicotine and tar. The increased risk of smoking is said to be positively correlated with the number of cigarettes smoked and with their tar and nicotine content [4], [9]. In Nigeria, it was been found that the cigarettes manufactured and sold in the Nigerian market have very high tar content with all of the fourteen brands analysed as at 1983 having more than $17 \mathrm{mg}$ or tar per cigarette [10]. This implies that there may be increased health risks in smoking cigarettes made in Nigeria. This study by Awotedu et al. was carried out about 30yrs ago and there are possibilities that the level of tar quoted may have changed [10]. However, the researchers could not lay hands on a more recent publication to review current levels of tar in the cigarettes specifically manufactured or marketed in Nigeria and this calls for research in this aspect of tobacco control. A recent study found low level of awareness about most of the constituents of tobacco among American adults aged 18 -66years [11].

This implication of cigarette smoking is worsened by the fact that the negative health consequences associated with smoking are not restricted to the smokers themselves. Passive smokers who must unavoidably be around those who smoke (that is, while the smoker is actively smoking) share and suffer from the health hazards of the tobacco smoke also [4]. People are sometimes not given in to believing how dangerous the habit of smoking cigarettes can be to themselves. Melgosa rightly considers tobacco as a drug with the lowest risk, in the short term but one which takes away health and life from the greatest number of people in the long term [12].

Though there are convincing evidences to support the negative health effects of cigarette smoking, it has been found that, knowledge about the health hazards of smoking has not always served to prevent people from smoking [13]. Smokers' low perception of the negative effects of their smoking behaviour on their health also results in many of them being unwilling to quit smoking [14]. A possible explanation for this attitude could be that most tobacco users are not fully aware of the harms caused by tobacco use [15] hence their underestimation of the ill-effects of smoking.

This study was aimed at ascertaining the level of knowledge of the health effects of cigarette smoking on health and wellbeing among young people aged between 18 to 24years in Southern Nigeria. The impact of this knowledge on the smoking behaviour of young smokers was also explored qualitatively. This study is part of the doctoral research of the first author. 


\section{METHOD}

\section{A. Study Design and Study Setting}

This study employed a mixed methods research design which involved both qualitative and quantitative methods of data collection. It was carried out in southern Nigeria. Southern Nigeria is divided into three geopolitical zones-GPZs (south-east, south-south and south-west zones) with a total of seventeen (17) out of the thirty-six states in Nigeria.

\section{B. Sample and Sampling Techniques}

Purposive sampling was used to recruit participants for the qualitative aspect of this study. Eighteen (18) young smokers (YS) aged between 18 and 24 years took part in the qualitative phase of this study. All the young smokers were males as the researchers were unable to recruit any female smoker to participate in the study due to an inability to access female smokers due to stigmatization of smoking among females (as mentioned by study participants). The mean age of the young smokers was 23 years while their mean age of smoking initiation was 15.2 years.

For the quantitative phase, a multi-staged non-probability sampling technique was used. Youth aged 18 to 24 years irrespective of their smoking status and gender formed the population for this phase. Participants were first stratified according to their Geopolitical zones (GPZs). Within the three GPZs in Southern Nigeria, participants were sampled along four strata namely; skilled workers, unskilled workers, undergraduate students and college students (students from tertiary institutions which were not universities e.g. Colleges of Education and Polytechnics). Cluster sampling was used for the participants who were undergraduates and college students. All willing students in a department within a faculty in the institution sampled participated in the survey. Skilled and unskilled workers were conveniently sampled at their places of work. Using the estimated prevalence of smoking of $32.8 \%$ in north-eastern Nigeria [16] with a $99 \%$ confidence interval, a minimum sample size of 585 was determined. Rounding this up to 600 and splitting among the three GPZs where the study was conducted yielded 200 respondents per GPZ (50 participants per category of respondents). However, after conducting a pilot study and experiencing about $86 \%$ return rate, the researchers decided to have an additional 10 participant per category for each GPZ. The final sample size involved in the survey was therefore 720 participants $(60$ participants per category of respondents). Only 550 participants formed the final sample of the survey participants. Seven participants were found to be above the age limit and 163 questionnaires were unreturned. Table I shows the breakdown of participants of both phases of the study.

\section{Data Collection}

Data collection spanned six months; February to July 2011. Eighteen individual interviews guided by semi-structured interview schedule were conducted in the qualitative phase of this study. The interview schedule had questions bordering on how the participants started smoking and their perception of the influence of culture, government policies, tobacco companies and other personal and social factors on their smoking behaviour as well as their knowledge of the health effects of smoking and how this has impacted on their smoking behaviour. Only results concerning participants' knowledge on the health effects of smoking and how this has impacted on their smoking behaviour are presented in this paper.

TABLE I: BREAKDOWN OF INTERVIEW AND SURVEY PARTICIPANTS

\begin{tabular}{|c|c|c|c|}
\hline & $\begin{array}{l}\text { Code name (for } \\
\text { qualitative } \\
\text { participants only) }\end{array}$ & $\begin{array}{l}\text { Qualitative } \\
\text { interviews }\end{array}$ & Survey \\
\hline Skilled workers & YS-SW & 5 & 119 \\
\hline $\begin{array}{l}\text { Unskilled workers } \\
\text { University }\end{array}$ & YS-USW & 6 & 128 \\
\hline \multirow{3}{*}{$\begin{array}{l}\text { Undergraduates } \\
\text { Students from other } \\
\text { tertiary institutions } \\
\text { (other students) }\end{array}$} & YS-US & 3 & 154 \\
\hline & YS-OS & 4 & 149 \\
\hline & $\begin{array}{l}\text { Total number of } \\
\text { participants }\end{array}$ & 18 & 550 \\
\hline
\end{tabular}

Interviews were conducted in English language and Nigerian Pidgin English spoken as a lingua franca across most parts of Nigeria especially in Southern Nigeria (the first author who conducted the interviews is very influent in speaking and writing the Nigerian Pidgin English). Participation was voluntary with participants formally consenting to the interview, recording and transcribing by signing an informed consent form. Ethical approval for this study was granted by the University of KwaZulu-Natal Research and Ethics Committee (HSS/1485/010D) as this study was part of a doctoral research undertaken in this institution. Transcription of the recorded interviews was done in the language the interviews were conducted after which those needing translation were translated into English language.

The quantitative data was collected using a structured questionnaire; a modified version of the Global Youth Tobacco Survey (MGYTS) questionnaire. The Global Youth Tobacco Questionnaire is a survey instrument designed by the World health organization to collect country-wide data on a wide range of issues around tobacco use among the youth [17]. Additional questions bordering on cultural issues around tobacco consumption were added to the original set of questions. However, aspects of the MGYTS specific to this paper explore participant's knowledge of the health effects of cigarette smoking. Responses to these questions were used to construct a knowledge index.

\section{The Knowledge Index}

The knowledge index was used to weigh the level of respondents' knowledge on the impact of smoking on health and well-being. Questions 17, 20, 23, 24, 28 and 29 of the MGYTS questionnaire were recoded into new variables according to their correctness (see details of these questions in Table II). Correct responses were coded as 2 and incorrect responses were coded as 1 . These questions were recoded as follows; question 17 ( $3 \& 4=2 ; 1 \& 2=1)$; question 20 ( $2=2 ; 1$ $\& 3=1)$; question $23(3=2 ; 1 \& 2=1)$; question $24(3 \& 4=2 ; 1$ \& 2=1); question 28 ( $1 \& 2=2 ; 3 \& 4=1)$; question 29 (3 $\& 4=2 ; 1 \& 2=1)$. See Table II for details on the construction of the knowledge index. These six items were summed to form the knowledge index with values ranging from 2 to 12 . The knowledge index was re-coded for analysis by categorizing the values to make arated knowledge index with 
values ranging from 2 to 7 rated as $1=$ low knowledge, 8 to 9

knowledge (see Table II). rated as $2=$ moderate knowledge and 10 to 12 rated as $3=$ high

TABLE II: KNOWLEDGE INDEX

\begin{tabular}{|c|c|c|c|c|}
\hline $\begin{array}{l}\text { Question No. in } \\
\text { the MGYTS } \\
\text { questionnaire }\end{array}$ & Question & Variables & Initial response options & Recoding \\
\hline 17 & $\begin{array}{l}\text { Once someone has started } \\
\text { smoking, do you think it would } \\
\text { be difficult to quit? }\end{array}$ & Knowledge 1 & $\begin{array}{l}1=\text { Definitely not; } 2= \\
\text { Probably not; } 3=\text { Probably } \\
\text { yes; } 4=\text { Definitely yes }\end{array}$ & $\begin{array}{l}1=\text { No (initial response options } 1 \& 2 \text { ) } \\
2=\text { Yes (initial response options } 3 \& 4 \text { ) }\end{array}$ \\
\hline 20 & $\begin{array}{l}\text { Does smoking cigarettes help } \\
\text { people feel more or less } \\
\text { comfortable at celebrations, } \\
\text { parties, or in other social } \\
\text { gatherings? }\end{array}$ & Knowledge 2 & $\begin{array}{l}1=\text { More comfortable; } 2= \\
\text { Less comfortable; } 3=\text { No } \\
\text { difference from non-smokers }\end{array}$ & $\begin{array}{l}1=\text { No (initial response options } 1 \& 3 \text { ) } \\
2=\text { Yes (Less comfortable) }\end{array}$ \\
\hline 23 & $\begin{array}{l}\text { Do you think that smoking } \\
\text { cigarettes makes you gain or lose } \\
\text { weight? }\end{array}$ & Knowledge 3 & $\begin{array}{l}1=\text { Gain weight; } 2=\text { Lose } \\
\text { weight; } 3=\text { No difference }\end{array}$ & $\begin{array}{l}1=\text { Yes }(\text { initial response options } 1 \& 2) \\
2=\text { No }\end{array}$ \\
\hline 24 & $\begin{array}{l}\text { Do you think cigarette smoking } \\
\text { is harmful to your health? }\end{array}$ & Knowledge 4 & $\begin{array}{l}1=\text { Definitely not; } 2= \\
\text { Probably not; } 3=\text { Probably } \\
\text { yes; } 4=\text { Definitely yes }\end{array}$ & $\begin{array}{l}1=\text { No (initial response options } 1 \& 2 \text { ) } \\
2=\text { Yes (initial response options } 3 \& 4 \text { ) }\end{array}$ \\
\hline 28 & $\begin{array}{l}\text { Do you think it is safe to smoke } \\
\text { for only a year or two as long as } \\
\text { you quit after that? }\end{array}$ & Knowledge 5 & $\begin{array}{l}1=\text { Definitely not; } 2= \\
\text { Probably not; } 3=\text { Probably } \\
\text { yes; } 4=\text { Definitely yes }\end{array}$ & $\begin{array}{l}2=\text { No }(\text { initial response options } 1 \& 2 \text { ) } \\
1=\text { Yes (initial response options } 3 \& 4 \text { ) }\end{array}$ \\
\hline \multirow[t]{2}{*}{29} & \multirow[t]{2}{*}{$\begin{array}{l}\text { Do you think the smoke from } \\
\text { other people's cigarettes is } \\
\text { harmful to you? }\end{array}$} & Knowledge 6 & $\begin{array}{l}1=\text { Definitely not; } 2= \\
\text { Probably not; } 3=\text { Probably } \\
\text { yes; } 4=\text { Definitely yes }\end{array}$ & $\begin{array}{l}1=\text { No }(\text { initial response options } 1 \& 2) \\
2=\text { Yes (initial response options } 3 \& 4 \text { ) }\end{array}$ \\
\hline & & Knowledge index & Values ranged from 2 to 12 & $\begin{array}{l}1=\text { low knowledge }(\text { values } 2-7) \\
2=\text { moderate knowledge (values } 8-9) \\
3=\text { high knowledge }(10-12)\end{array}$ \\
\hline
\end{tabular}

\section{E. Data Analysis}

Qualitative data analysis was informed by an interpretative phenomenological approach [18]. Coding of the data was informed by apriori concepts in the interview schedule as well as new emergent themes from the interviews. The software Nvivo 9 was used in organising the data into themes and subthemes. Two independent coders were engaged to enhance rigor in the coding exercise and validity of the emergent themes.

Quantitative data was analysed using the Statistical Package for the Social Sciences (SPSS) version 21 software. The Chi-square test $\left(\chi^{2}\right)$ was used to examine the association between knowledge of the health effects of smoking and other demographic variables like gender, age, smoking status, geo-political zone of residence and of origin, trial smoking, educational attainment, intention to quit and quit attempts in the past year, employment category (students vs skilled and unskilled workers). A $p$-value of $\leq 0.05$ was considered statistically significant.

\section{RESULtS}

\section{A. Qualitative Results}

\section{1) Awareness of the health hazards of cigarette smoking}

There was generally a moderate level of awareness about specific health hazards associated with smoking across participants in this study. Most respondents were however able to mention one or more health hazards associated with the habit. Some of these health challenges as mentioned by respondents include; various types of cancers, cough, tuberculosis, "heart problem", "kidney problems", hypertension, glycoma etc. Though the young participants reported being aware that smoking is dangerous to health, some believed that some people's body systems are less tolerant to cigarette smoking than others making it dangerous for such people and not necessarily everyone.

"Of course there are health problems associated with smoking... my uncle stopped smoking because he had emm...glycoma and I think it causes lung problem too. (YS-OS 1; Male)."

"Health hazard?...depending on the person. Some people their blood does not want that kind of smoking, so it depends ....like those people that their blood does not want it, they could have plenty diseases.( YS-OS 2; Male)."

\section{2) Attitude of young smokers towards health warnings on cigarette smoking}

Qualitative findings reveal a multiplicity of attitudes towards the health messages on cigarette smoking. Some young smokers believed these health messages and even sought to reduce their daily consumption of cigarette while others resorted to taking foods perceived to reduce the risk associated with smoking. However, some young smokers expressed total disbelief of these health messages or assumed an attitude of resignation to whatever fate may befall them on account of their smoking habit.

\section{3) Reduction in the number of cigarettes consumed daily}

A few of the young smokers interviewed reported reducing the number of cigarette sticks they smoke in a day as a way of forestalling the impact it will have on their health. One young smoker reported taking precautionary measures against these health risks by eating foods that are known to reduce the risk of cancer.

"...before I can smoke like 20 sticks per day...but after I 
read the message, I wanted to stop smoking but I couldn't stop because I'm now addicted to it...so I then reduced the number I smoke. Now, I smoke sometimes... 7 or 6 sticks...but I don't smoke more than 7 in a day. (YS-USW 3; Male)."

"From what I heard about garlic, vegetables, fruits, you see...they tend to reduce your chances of having cancer so...if cigarette smoking tend to increase your chances of getting cancer, and these food items tend to reduce your chances of getting cancer, so at the end of the day you are where you...if this one pushes you to the left and this one to the right, at the end of the day, you are where you...you remain where you are [i.e. healthy].Yeah I eat fruits a lot. It's not really about...I like eating it but it's not really about reducing my chances but I know it's one of the reasons why I eat them but I like eating fruits a lot...particularly garlic. Garlic is not a fruit but you know the qualities of...garlic. (YS-US 2; Male)."

\section{4) Disbelief of the health warnings on smoking}

On another hand, some young smokers expressed a complete disbelief of the health warnings written on cigarette packs and adverts. Participant YS-OS2 (male) believes that smokers even live longer than non-smokers in contradiction to the health warning on cigarette packs; "The Federal Ministry of Health warns that smokers are liable to die young".

"No...these messages do not affect my smoking. They will not ... in the sense that...I have told you about the LUTH...that is, the Lagos University Teaching Hospital. How doctors come there to smoke. So if doctors could smoke...doctors that are so aware about this health hazards...they are in this too. They are in the medical field so they are supposed to know these things. So if some of them are nonchalant about it, that means probably in the research there are some loop holes they themselves have noticed... that's one. Two... emm...I really don't know...I really don't think so. It [the health warning] is not convincing enough. It is not correct in the sense that, my father smoked till he died and he was about 70 plus when he died. 70yrs plus...and it was not even the cigarette smoke that killed him, it was the alcohol. He had stroke and cigarette does not come with stroke (YS-US 2; Male)."

\section{5) Fatalistic attitude - the "anything can kill a man" syndrome}

A fatalistic attitude among young smokers was found expressed in the slogan "anything can kill a man" or "a man must die of something". This slogan was used by some participants when asked how the negative health implications of cigarette smoking impact on their own smoking behaviour. This slogan (in the Pidgin English parlance) connotes a resignation or a readiness to face the health consequences of smoking if they do eventually set in. It is also used by smokers to dissuade those who try to educate them about the health consequences of smoking.

"Well, I have this conception that emm...anything can kill a man, (YS-SW 5; Male)."

"I know that a man must die of something. Either he dies through working, accident, smoking, drinking water, drinking beer, malaria... a man must die of something, (YS-SW 2; Male)."

\section{B. Survey Results}

Descriptive statistics carried out to ascertain the participants' knowledge of the negative impact of smoking on health and well-being (using the knowledge index) showed that respondents' level of knowledge on this measure was generally high with slightly more than half $(56.1 \%, n=$ 305 ) falling within the high knowledge category, $32.4 \%(n=178)$ had a moderate level of knowledge while $11.2 \%(n=61)$ had low level of knowledge. Chi-square test for independence was used in investigating respondents' knowledge levels with their demographic characteristics and smoking behaviours. Cross-tabulation results are presented in Table III. Note that to determine the strength of the association between the various variables; all effect sizes reported here are those of Cramer's $V\left(\varphi_{c}\right)$. Results are presented under various demographic characteristics.

Smoking status: Comparing smokers and non-smokers on their level of knowledge, the results show that non-smokers were more likely to have a higher knowledge of the negative impact of smokingon health and well-being than smokers $(66.8 \%, n=250$ versus $31.4 \%, n=50)$. The chi-square test for independence showed a statistically significant association between smoking status and knowledge levels $\left(\chi^{2}[2, n=\right.$ $533=79.30, p<0.001)$. The effect size $\left(\varphi_{c}=.39\right)$ revealed that the strength of the association is medium.

Gender: Regarding gender and knowledge levels, females were more likely to have a high knowledge about the negative impact of smoking on health and well-being than males $(65.4 \%, n=102$ versus $51.7 \%, n=193)$ ). The results of the chi-square test for independence showed a significant association between gender and knowledge levels

Employment status: Considering youth's employment status and their knowledge levels, students were more likely to have obtained a high knowledge level about the impact of smoking on health and well-being $(65.1 \%, n=196)$ than skilled and unskilled workers $(58.3 \%, n=67$ and $32.8 \%, n=42$ respectively). There was a statistically significant association between the respondents' employment status and their levels of knowledge based on the results from the chi-square test of independence $\left(\chi^{2}[d 4, n=544]=\right.$ $\left.56.63, p \lambda<0.001, \varphi_{c}=23\right)$. The effect size obtained however indicated a small associationof the respondents $\left(\chi^{2}[2, n=520]=11.98, p=0.03\right)$. The effect size $\left(\varphi_{c}=15\right)$ however showed a small association between these variables.

Age: An investigation of respondents' knowledge level by age showed that more youth aged 21 years fell within the high knowledge category $(63.8 \%, n=37)$ followed closely by those aged 22 years $(62.5 \%, n=35)$. The chi-square test for independence however found no significant relationship between age and knowledge levels among the respondents $\left(\chi^{2}[12, n=520]=11.88, p=0.456, \varphi_{c}=0.11\right)$.

Trial behaviour: In comparing the level of knowledge among the youth who have ever tried smoking with those who have not, it was found that those who have never tried smoking were more likely to have a higher level of knowledge than those who have tried $(68.6 \%, n=$ 218 versus $37.8 \%, n=84$ ). 
TABLE III: CROSS-TABULATION OF KNOWLEDGE LEVELS WITH DEMOGRAPHIC MEASURES AND SMOKING BEHAVIOUR

\begin{tabular}{|c|c|c|c|c|c|c|}
\hline \multirow{2}{*}{ Variable } & \multirow{2}{*}{ Category } & \multicolumn{3}{|c|}{ Rated level of knowledge } & \multirow{2}{*}{ Group total $(100 \%)$} & \multirow{2}{*}{$N$} \\
\hline & & Low $(\%)$ & Moderate $(\%)$ & High (\%) & & \\
\hline \multirow[t]{2}{*}{ Smoking Status* } & Non-Smoker & $17(4.5 \%)$ & $107(28.6 \%)$ & $250(66.8 \%)$ & 374 & \multirow[t]{2}{*}{533} \\
\hline & Smoker & $42(26.4 \%)$ & $67(42.1 \%)$ & $50(31.4 \%)$ & 159 & \\
\hline \multirow[t]{2}{*}{ Gender* } & Male & $52(13.9 \%)$ & $128(34.3 \%)$ & $193(51.7 \%)$ & 373 & \multirow[t]{2}{*}{529} \\
\hline & Female & $8(5.1 \%)$ & $46(29.5 \%)$ & $102(65.4 \%)$ & 156 & \\
\hline \multirow{7}{*}{ Age } & 18 years & $5(28.3 \%)$ & $7(33.3 \%)$ & $9(42.9 \%)$ & 21 & \multirow{7}{*}{520} \\
\hline & 19 years & $7(14.3 \%)$ & $15(30.6 \%)$ & $27(55.1 \%)$ & 49 & \\
\hline & 20 years & $12(14.5 \%)$ & $30(36.1 \%)$ & $41(49.4 \%)$ & 83 & \\
\hline & 21 years & $5(8.6 \%)$ & $16(27.6 \%)$ & $37(63.8 \%)$ & 58 & \\
\hline & 22 years & $7(12.5 \%)$ & $14(25.0 \%)$ & $35(62.5 \%)$ & 56 & \\
\hline & 23 years & $9(10.3 \%)$ & $27(31.0 \%)$ & $51(58.6 \%)$ & 87 & \\
\hline & 24 years & $13(7.8 \%)$ & $62(37.3 \%)$ & $91(54.8 \%)$ & 166 & \\
\hline \multirow{3}{*}{$\begin{array}{l}\text { Employment } \\
\text { Category* }\end{array}$} & Student & $20(6.6 \%)$ & $85(28.2 \%)$ & $196(65.1 \%)$ & 301 & \multirow{3}{*}{544} \\
\hline & Skilled worker & $7(6.1 \%)$ & $41(35.7 \%)$ & $67(58.3 \%)$ & 115 & \\
\hline & Unskilled worker & $34(26.6 \%)$ & $52(40.6 \%)$ & $42(32.8 \%)$ & 128 & \\
\hline \multirow{2}{*}{ Trial behaviour* } & Yes & $48(21.6 \%)$ & $90(40.5 \%)$ & $84(37.8 \%)$ & 222 & \multirow[t]{2}{*}{540} \\
\hline & No & $13(4.1 \%)$ & $87(27.4 \%)$ & $218(68.6 \%)$ & 318 & \\
\hline \multirow{4}{*}{ GPZorigin* } & South-east & $27(15.1 \%)$ & $68(38.0 \%)$ & $84(46.9 \%)$ & 179 & \multirow{4}{*}{540} \\
\hline & South-south & $14(9.0 \%)$ & $47(30.3 \%)$ & $94(60.6 \%)$ & 155 & \\
\hline & South-west & $15(8.7 \%)$ & $49(28.3 \%)$ & $109(63.0 \%)$ & 173 & \\
\hline & Others & $5(15.2 \%)$ & $13(39.4)$ & $15(45.5 \%)$ & 33 & \\
\hline \multirow{3}{*}{ GPZresiding* } & South-east & $28(16.6 \%)$ & $61(36.1 \%)$ & $80(47.3 \%)$ & 169 & \multirow{3}{*}{544} \\
\hline & South-south & $18(9.0 \%)$ & $62(31.0 \%)$ & $120(60.0 \%)$ & 200 & \\
\hline & South-west & $15(8.6 \%)$ & $55(31.4 \%)$ & $105(60.0 \%)$ & 175 & \\
\hline \multirow{2}{*}{$\begin{array}{l}\text { Educational } \\
\text { attainment }\end{array}$} & Basic education & $53(12.4 \%)$ & $137(32.1 \%)$ & $237(55.5 \%)$ & 427 & \multirow{2}{*}{542} \\
\hline & Tertiary education & $7(6.1 \%)$ & $41(35.7 \%)$ & $67(58.3 \%)$ & 115 & \\
\hline \multirow{2}{*}{$\begin{array}{l}\text { Smokers' intention } \\
\text { to quit: }\end{array}$} & No & $23(45.1 \%)$ & $15(29.4 \%)$ & $13(25.5 \%)$ & 51 & \multirow[b]{2}{*}{106} \\
\hline & Yes & $4(7.3 \%)$ & $33(60.0 \%)$ & $18(32.7 \%)$ & 55 & \\
\hline \multirow{2}{*}{$\begin{array}{l}\text { Smokers' attempt } \\
\text { to quit in past year }\end{array}$} & No & $30(52.6 \%)$ & $16(28.1 \%)$ & $11(19.3 \%)$ & 57 & \multirow{2}{*}{120} \\
\hline & Yes & $6(9.5 \%)$ & $33(52.4 \%)$ & $24(38.1 \%)$ & 63 & \\
\hline
\end{tabular}

*significant at $p<.05 ; * * p<.01 ; * * * p<.001$ (two-tailed) $\left(\chi^{2}\right.$ test for independence);

tonly smokers used for cross-tabulation and $\chi^{2}$ test

The chi-square test for independence used to explore respondents' trial behaviour and their knowledge level regarding the negative impact of smoking on health and wellbeing, revealed a statistically significant relationship between these variables $\left(\chi^{2}[2, n=540]=64.56, p<\right.$ $\left.0.001, \varphi_{c}=35\right)$. The strength of this relationship was found to be medium.

Geopolitical zones (GPZs) of origin and residence: The chi-square test was also conducted to investigate the level of knowledge among the youth from the three GPZs showed a significant relationship between youth's GPZ of origin and their knowledge levels $\chi^{2}[6, n=540]=13.13, p<$ $\left.0.041, \varphi_{c}=11\right)$. The youth who come from the south-west GPZ were more likely to have a high knowledge level $(63 \%, n=10)$ than the youth from the other two $\operatorname{GPZs}(60.6 \%, n=94)$ for the south-south and $46.9 \%, n=$ 84 for the south-east).
The results also showed a significant relationship between the knowledge levels and respondents' GPZ of residence $\left(\chi^{2}[4, n=544]=10.47, p<0.033, \varphi_{c}=10\right)$. The youth residing in the south-south $\operatorname{GPZ}(60 \%, n=120)$ as well as those in the south-west $(60 \%, n=105)$ were more likely to have higher knowledge levels than those residing in the south-east GPZ $(47.3 \%, n=80)$. The effect sizes between the respondents' level of knowledge and their GPZ of origin as well as with their GPZ of residence indicated a small effect for both relationships.

Educational attainment: In the cross tabulation of knowledge levels by educational attainment, it is noted that slightly more respondents who have attained a tertiary education $(58.3 \%, n=67)$ fell within the higher knowledge category than those who have had a basic (primary and secondary) education $(55.5 \%, n=237)$. However, the chi-square test of independence found no significant 
relationship between respondents' educational attainment and their knowledge levels $\chi^{2}[2, n=542]=3.75, p=$ $\left.15, \varphi_{c}=0.08\right)$.

Intention to quit smoking: Among participants who were smokers, more smokers who indicated an intention to quit smoking were found to have a higher knowledge level than those who indicated no intention to quit $(32.7 \%, n=$ 18 versus $25.5 \%, n=13$. A significant relationship was detected by the chi-square test between smokers' intention to quit and their knowledge level $\left(\chi^{2}[2, n=106]=\right.$ $\left.20.81 ;, p<0.011, \varphi_{c}=0.44\right)$. The effect size obtained showed that the relationship had a medium to large effect

Quit attempt in the past year: More smokers who had attempted to quit in the past year were in the high knowledge category than those who had not attempted to quit(38.1\%, $n=24$ versus $19.3 \%, n=11)$. A significant relationship between smokers' quit attempt in the past year and their level of knowledge was detected by the chi-square test for independence $\left(\chi^{2}[2, n=120]=26.49 ; p<\right.$ $\left.0.001, \varphi_{c}=47\right)$. The effect size showed a medium to large effect (see Table III).

\section{DISCUSSION}

Though most young smokers interviewed could recount some of the health hazards associated with smoking, they expressed a sense of invincibility (which also characterizes youth's risk taking tendencies) when asked how this knowledge has influenced their smoking behaviour. There seems to be an under-estimation of the negative health effects of smoking or that these health effects are largely long term and therefore should not be an immediate cause for concern.

Most of the young smokers interviewed could actually mention some of the long term effects of smoking e.g. the risk of various types of cancer. Nevertheless, some smokers also believed that these risks can be reduced by a reduction in cigarette consumption and/or by eating healthy. On the other hand, some actually made efforts to reduce the number of cigarettes they consume per day as a way of protecting themselves from the negative health consequences of smoking. Some of the smokers also seem to have resigned themselves to fate. They had even constructed a slogan; "anything can kill a man" to express this resignation in their own way. This slogan was used to express the fact that all humans must eventually have to face death someday and somehow. It is also used to express their fatalistic attitude towards the negative health consequences of their smoking behaviour. Consequently, these smokers expressed the belief that cigarette smoking is not the only source of death and should not carry as much concern as it presently does. In a study by Hussain et al., it was found that the knowledge of the adverse effects of cigarette smoking did not translate to a lower prevalence in smoking among Nigerian Soldiers [13]. Dinn, Aycicegi and Harris therefore assert that smoking behaviour may reflect to some degree, a diminished ability to anticipate the long term negative consequences of tobacco use [19].

In a study by Morell, Song and Halpern-Felsher, it was found that adolescents who had personal smoking experiences viewed smoking to be less risky and was more likely to report on the benefits of smoking over time [20]. These authors therefore suggested that these alterations in risk perception by smokers may possibly be as a result of the sensational and seemingly positive effect of smoking on such individuals [20] which in turn may be due to the psychoactive properties of some of the components of cigarettes.

Findings from the survey conducted in this research also confirm that just over half of young people (about 56\%) have high knowledge levels about the negative impact of smoking on health and well-being. However, this was significantly higher in the following subgroups; non-smokers, females, students, respondents who have never experimented with smoking and those who come from and reside in the south-west GPZ as well as those who reside in the south-south GPZ.

From the results obtained, a conclusion cannot be made concerning the relationship between knowledge levels and smoking status per se. However, high knowledge level with regards to the impact of smoking on health and well-being seems to be positively associated with the youth in terms of their employment category (students versus unskilled workers), gender (females versus males) and respondents' GPZs of origin and of residence (the South-south and South-west versus the South-east in both cases). On the other hand, those who have never experimented with smoking and those who do not currently smoke were also found to have higher levels of knowledge suggesting that their knowledge levels may have influenced their choice of not smoking. Findings regarding the perceptions of the negative health implications of smoking as they relate to actual smoking behaviour is consistent with those from previous studies conducted in Nigeria by [13], [14], [21]. Knowledge of the harmful effect of smoking was also found to be generally high among students of institutions of higher learning in the Eastern Cape Province of South Africa [22].

\section{CONCLUSION/RECOMMENDATIONS}

Young smokers' knowledge of the health effects of cigarette smoking is pivotal in tobacco control especially among those within this growth stage. Though research has shown the inadequacy in current health messages from achieving the desired impact in terms of a reduction in smoking initiation and quitting attempts, this research offers renewed hope as to the effect such health messages may have in the long run. The fact that most of the young smokers who have attempted quitting or have the intention to quite tend to have a high level of knowledge of the health effects of cigarette smoking is a case in point.

It is possible that there is need to review current health warnings on tobacco consumption which may not have been tailored for this category of the audience (the youth). Health promotion practitioners have a task in hand to explore other ways of designing youth-friendly adverts seeking to discourage youth from picking up the habit of smoking and encouraging those already smoking to quit the habit.

Health practitioners who smoke need to be aware that while it is a personal decision whether to smoke or not, their attitude towards smoking can and does influence younger people in their decision whether to believe health warnings on cigarette smoking or not. This should serve as a wake-up 
call to health practitioners to be more responsive in the fight against tobacco and to lead by example.

In all, there can never be too much awareness on the health effects of cigarette smoking. There is need to continue to and improve on current efforts aimed at reducing tobacco consumption to the barest minimum especially among the young population. Smoking cessation clinics are still very essential to help the youth who need assistance to be able to quit smoking.

\section{REFERENCES}

[1] S. Atawodi, R. Preussmann, and B. Spiegelhalder, "Tobacco-specific nitrosamines in some Nigerian cigarettes," Cancer Letters, vol. 97, no. 1, pp. 1-6, 1995

[2] O. Desalu, A. Olokoba, A. Danburam, F. Salawu, and B. Issa, "Epidemiology of tobacco smoking among adults population in North-East Nigeria," The Internet Journal of Epidemiology, vol. 6, no. $1,2008$.

[3] O. Fakoya. (February 2010). Nigeria: The Health, Economic and Social Menace of Smoking - Time for Concerted Actions. [Online]. Available:

http://www.nigeriavillagesquare.com/articles/guest-articles/.

[4] Preventing tobacco use among youth and young adults: a report of the surgeon general, U.S. Department of Health and Human Services, Atlanta, 2012.

[5] E. C. Hammond and D. Horn, "Smoking and death rates-report on forty - four months of follow - up of 187,783 men," CA: A Cancer Journal for Clinicians, vol. 38, pp. 28-58, 1988.

[6] M. P. Eriksen, C. A. L. Maistre, and G. R. Newell, "Health hazards of passive smoking," Annual Review of Public Health, vol. 9, pp. 47-70, 1988.

[7] C. Humble, J. Croft, A. Gerber, M. Casper, C. G. Hames, and H. A. Tyroler, "Passive smoking and 20-year cardiovascular disease mortality among non-smoking wives, evans county, georgia," American Journal of Public Health, vol. 80, pp. 599-601, 1990.

[8] O. P. Almeida, G. J. Garrido, H. Alfonso, G. Hulse, N. T. Lautenschlager, G. J. Hankey et al., "24-Month effect of smoking cessation on cognitive function and brain structure in later life," Neuroimage, vol. 55, no. 4, pp. 1480-1489, 2011.

[9] W. Weiten, Psychology Themes and Variations, California, Brooks/Cole, p. 497,1989.

[10] A. Awotedu, T. Higenbottam, and B. Onadeko, "Tar, nicotine, and carbon monoxide yields of some Nigerian cigarettes," Journal of Epidemiology and Community Health, vol. 37, pp. 218-220, 1983.

[11] M. G. Hall, K. M. Ribisl, and N. T. Brewer, "Smokers' and nonsmokers' beliefs about harmful tobacco constituents: implications for FDA communication efforts," Nicotine and Tobacco Research, vol. 16, pp. 343-350, March 1, 2014.

[12] J. Melgosa, Developing a Healthy Mind, Spain: Editorial Safeliz, p. 134, 2007.

[13] N. Hussain, T. Akande, and O. Adebayo, "Prevalence of cigarette smoking and the knowledge of its health implications among Nigerian soldiers," East African Journal of Public Health, vol. 6, no. 2, pp. $168-170,2009$

[14] A. Fawibe and A. Shittu, "Prevalence and characteristics of cigarette smokers among undergraduates of the University of Ilorin, Nigeria," Nigerian Journal of Clinical Practice, vol. 14, no. 2, pp. 201-205, 2011.
[15] W. H. Organization, WHO Report on the Global Tobacco Epidemic, 2011: Warning About the Dangers of Tobacco, 2011.

[16] F. Salawu, A. Danburam, B. Isa, and J. Agbo, "Cigarette smoking habits among adolescents in northeast Nigeria," Internet Journal of Epidemiology, vol. 8, no. 1, 2010.

[17] Smoking and Tobacco Use. Global Youth Tobacco Survey: Core Questionnaire. (2008). [Online]. Available: http://www.cdc.gov/tobacco/global/gyts/intro.htm

[18] L. Storey, "Doing interpretative phenomenological analysis," Analysing Qualitative Data in Psychology, 2007, pp. 51-64.

[19] W. M. Dinn, A. Aycicegi, and C. L. Harris, "Cigarette smoking in a student sample: Neurocognitive and clinical correlates," Addictive Behaviors, vol. 29, pp. 107-126, 2004.

[20] H. E. Morrell, A. V. Song, and B. L. Halpern-Felsher, "Predicting adolescent perceptions of the risks and benefits of cigarette smoking: A longitudinal investigation," Health Psychology, vol. 29, no. 6, pp. 610-617, 2010.

[21] O. Desalu, K. Iseh, A. Olokoba, F. Salawu, and A. Danburam, "Smokeless tobacco use in adult Nigerian population," Nigerian Journal of Clinical Practice, vol. 13, no. 4, pp. 3842-387, 2010.

[22] A. Awotedu, E. Jordaan, O. Ndukwana, N. Fipaza, K. Awotedu, J. Martinez et al., "The smoking habits, attitudes towards smoking and knowledge regarding anti-smoking legislation of students in institutions of higher learning in the Eastern Cape Province of South Africa: original research," South African Family Practice, vol. 48, no. 9 , pp. 14, 14a-14d, 2006.

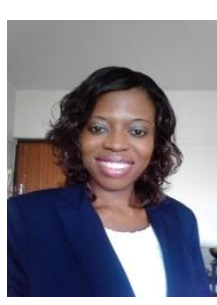

Catherine O. Egbe is currently a research psychologist at the University of Kwa Zulu-Natal, Durban, South Africa. Her areas of research interest include mental health promotion (specifically psychiatric stigma) and tobacco control as well as youth and adolescents' research. She has a bachelor of science education degree in biology/education and a master's degree in guidance and counselling both from the University of Benin, Edo State, Nigeria. She was awarded her $\mathrm{PhD}$ in 2013 from the University of KwaZulu-Natal, Durban, South Africa where she currently works as a postdoctoral research fellow and a part time lecturer. She has published several articles on psychiatric stigma and discrimination, tobacco control and HIV/AIDS in reputable International journals.

Inge Petersen is a professor in the discipline of psychology at the University of KwaZulu-Natal, Durban, South Africa. She received her doctorate in the field of community mental health from the University of Cape Town, South Africa. Her research interests include mental health promotion and risk reduction as well as mental health systems reform for integrated primary mental health care.

Anna Meyer-Weitz is a professor in the discipline of psychology (promotion programme) at the University of KwaZulu-Natal, Durban, South Africa. She received her doctorate in health promotion and health education from university of Maastricht, Netherlands. Her major research interests include critical health promotion and behaviour change for better health, adolescent and sexual health, HIV/AIDS. 